\title{
LA HISTORIA DEL CURRÍCULUM \\ EN ESPANAA: LA RURALIDAD DUAL DE UN SUBCAMPO TODAVÍA EN CONSTRUCCIÓN
}

\section{Curriculum History in Spain: the dual rurality of a subfield still under construction}

Jesús Romero Morante

Correo-e: romeroj@unican.es

Marta Estellés FRADE

Universidad de Cantabria

Correo-e: marta.estelles@unican.es

Recibido: Is de julio de 2020. Envío a informantes: 23 de julio de 2020.

Aceptación definitiva: II de octubre de 2020

Resumen: La historiografía del currículum y de las asignaturas escolares no tiene una larga tradición en España. Es más, todavía en la actualidad constituye un foco de interés comparativamente marginal dentro de la tribu académica de los historiadores de la educación, hasta el punto de que algunos de sus frutos más substanciosos se han cosechado fuera de ese ámbito. Sin embargo, no es el propósito de este artículo hacer un estado de la cuestión al uso, sino revisar críticamente las presuposiciones y los sobrentendidos implícitos acerca de la naturaleza y la dinámica del currículum que subyacen a las investigaciones emprendidas en este país en las últimas décadas.

Palabras Clave: historia del currículum; España; conocimiento escolar; historia de las asignaturas escolares.

AвSTRACT: The historiography of curriculum and school subjects does not have a long tradition in Spain. Even today it is still a comparatively marginal focus of interest within the academic tribe of Spanish education historians, to the point that some of its most substantial fruits have been harvested outside that field. However, it is not the purpose of this article to carry out a usual review of the state of the art. Instead, a critical dissection of the implicit presuppositions and understandings 
about the nature and dynamics of the curriculum which underlie the research undertaken in this country in recent decades will be attempted.

KEY WORDS: curriculum history; Spain; school knowledge; history of school subjects.

\section{Tierra de todos y de nadie}

$\mathrm{E}$ N SU CONOCIDO TRABAJO de sociología de la ciencia, Tony Becher ${ }^{\mathrm{I}}$ llamaba la atención sobre uno de los habituales atajos metafóricos del lenguaje, naturalizados a fuerza de uso, de los que se sirven las comunidades académicas para hablar acerca de sus respectivas disciplinas y especialidades. En concreto, la tendencia espontánea a pensar sus ámbitos de estudio cual paisajes humanizados, a través de una red tácita de analogías territoriales: campos, subcampos o parcelas, fronteras y "patriotismos disciplinares», pioneros en la roturación de nuevos predios, hitos en el camino, etc. Después de todo, la relación entre «tribus» y «territorios» dice mucho de la organización social del conocimiento y aun del propio conocimiento producido. Bien entendido que dicha relación es variable, amén de cambiante. Por mencionar los casos extremos, en un polo los derechos de propiedad exclusiva sobre un terruño se defienden con tal energía que la división interno-externo queda, no sin conflictos, trazada con murallas y puertas fortificadas en el mapa universitario. En el otro polo nos encontramos con encrucijadas abiertas que, por sus contornos imprecisos y la mayor laxitud en su custodia, se convierten en zonas de tránsitos múltiples, con orígenes y destinos diversos. Las jerarquías y controles intramuros se diluyen parcialmente en estos márgenes todavía no cercados (del todo), circunstancia que puede llegar a propiciar con mayor probabilidad relativa -sin garantizarlo en absoluto- el surgimiento de miradas innovadoras y el diálogo interdisciplinar. Pero esa cara potencial arrastra su cruz. Los transeúntes de lo que, en un determinado momento, son tierras de nadie se ven alejados del sistema de estímulos y recompensas operante en el núcleo de los gremios, y ese es uno de los factores que ayuda a explicar la desigual densidad de población académica en unas áreas y otras. Las ubicadas dentro del perímetro delimitado por la tribu se urbanizan y ganan glamur metropolitano, mientras las excéntricas han de acostumbrarse a la vida rural.

La historia del currículum ha sido presentada como «uno de los resultados más significativos de la renovación operada en la Historia de la Educación desde finales de los años sesenta» del siglo $\mathrm{XX}^{2}$. La afirmación puede ser atinada en el mundo anglosajón, Suecia, Francia, Alemania y, tal vez, otras latitudes, pero no refleja exactamente lo acontecido en España. Siguiendo con el símil de Becher,

BeCher, T.: Tribus y territorios académicos. La indagación intelectual y las culturas de las disciplinas, Barcelona, Gedisa, 200I.

VV. AA.: El currículum: historia de una mediación social y cultural, vol. I, IX Coloquio de Historia de la Educación, Granada, Ediciones Osuna, 1996, p. 7. 
para localizar esta especialización en suelo hispano sería menester recurrir a la cartografía catastral rústica. Este terrazgo no ha sido hasta la fecha objeto de una singular predilección, se ha sembrado de manera irregular -aunque algunos regadíos exuberantes dan lustre a la campiña, abundan los secanos y los barbechos- y solo una parte de la cosecha es atribuible a los historiadores de la educación.

El propósito de este artículo es, precisamente, describir las peculiaridades de ese desarrollo disparejo y someter a discusión algunos problemas que, a nuestro juicio, se derivan del mismo. En otras palabras, la lectora o el lector no encontrará aquí un repaso veloz de todo lo publicado ni un estado de la cuestión al uso. Ya existen algunos muy bien documentados y analíticamente clarificadores ${ }^{3}$, de enorme utilidad para hacerse una composición de lugar, a los cuales remitimos con nuestras excusas por las injustas omisiones de nombres y obras en las que vamos a incurrir. Lo que nos interesa, en su lugar, es buscar en el desenvolvimiento de este subcampo en nuestro país factores que contribuyan a explicar algunas debilidades detectadas.

Obviamente, los diagnósticos no son neutros ni inocentes. Además, siquiera en parte, son tributarios de la posición ocupada por quienes enjuician. Urgen, por ese motivo, varias aclaraciones. Los autores de estas páginas han emprendido desde hace años modestas indagaciones sobre la historia de algunas materias escolares, pero no son historiadores de la educación. Su tribu es la Didáctica de las Ciencias Sociales ${ }^{4}$. Quizá esta adscripción ayude a entender mejor por qué no se pondrá el foco principal en las preferencias temáticas, de nivel educativo y período cronológico de la literatura alumbrada, o en las modas y discrepancias historiográficas explícitas. Por el contrario, la pretensión última de nuestra revisión es sacar a la luz los presupuestos que han tendido a darse implícitamente por sentados al tiempo de construir este objeto de estudio. Semejante decisión,

Véanse, en especial, los debidos a la pluma de Antonio Viñao Frago: VIÑAO, A.: «La historia de las disciplinas escolares», Historia de la Educación, 25 (2006), pp. 243-269; VIÑAO, A.: «La enseñanza secundaria», en Guereña, J.-L.; Ruiz Berrio, J. y Tiana Ferrer, A. (eds.): Nuevas miradas historiográficas sobre la educación en la España de los siglos XIX y XX, Madrid, Ministerio de Educación, Cultura y Deporte, 20Io, pp. IO7-I42; o GonzÁlez Delgado, M. y Woyshner, C. A.: «Disciplinas escolares y cultura escolar: una conversación con el profesor Antonio Viñao Frago en torno a la historia del currículum en España», Espacio, Tiempo y Educación, 4(2) (2017), pp. 373-386. Otras lecturas obligadas son el primer capítulo del libro de CUESTA, R.: Sociogénesis de una disciplina escolar: la Historia, Barcelona, Pomares-Corredor, 1997; y varios trabajos de Rafael Valls Montés, en particular VAlls, R.: «De los manuales de Historia a la historia de la disciplina escolar: nuevos enfoques en los estudios sobre la historiografía escolar española», Historia de la Educación, i8 (1999), pp. I69-190; VALLS, R.: «La historiografía escolar española en la época contemporánea: de los manuales de Historia a la historia de la disciplina escolar», en ForCadell, C. y Peiró, I. (coords.): Lecturas de historia. Nueve reflexiones sobre historia de la historiografía, Zaragoza, Institución Fernando el Católico (CSIC) y Excma. Diputación de Zaragoza, 200I, pp. I9I-220; o VAlls, R.: Historiografía escolar española: siglos XIX y XX, Madrid, UNED, 2007.

4 Miembros del grupo Asklepios, ambos pertenecen asimismo a la Federación Icaria (Fedicaria), una asociación autogestionada de profesores de todas las etapas educativas cuyo común denominador son las teorías críticas de la educación y de la cultura. Véase http://www.fedicaria.org. 
nada caprichosa, demanda una aclaración adicional. Consiéntasenos al respecto un pequeño rodeo.

Como es sabido, el británico Ivor F. Goodson-seguramente el exponente más ilustre de la historia social de las asignaturas escolares- perfiló en su obra seminal de 1983, y afinó en otras posteriores', una serie de hipótesis sobre la morfología evolutiva de las disciplinas en el trance de abrirse un hueco en el syllabus y consolidarse en él. Una morfología evolutiva que revela un desplazamiento desde la inicial autojustificación en términos pedagógicos y utilitarios a la promoción y cultivo de valores «académicos» como forma de perseguir territorio, estatus y mejores perspectivas profesionales. Salvando las distancias y con la debida cautela, algunos términos de la hipótesis son aplicables al caso que nos incumbe. $\mathrm{Al}$ decir de Viñao ${ }^{6}$, el gremio español de historiadores de la educación reconoció oficialmente la historia del currículum como ámbito de investigación propio, dotado de cierta autonomía, al dedicarle monográficamente el IX Coloquio de su sociedad científica, celebrado en Granada en 1996. Considerando que la Historia de la Educación tiene su anclaje institucional en las facultades responsables de la formación inicial del profesorado, no sorprende que en la introducción a las actas de dicho coloquio ${ }^{7}$ se patrocinase abiertamente la historia del currículum como «una historia más pertinente para los docentes, más genuinamente útil para comprender y explicar la realidad educativa». El mismo Viñao, en un artículo importante ${ }^{8}$, saludaba su potencial para «tender puentes [...] entre el mundo académico de la ciencia pedagógica y el mundo empírico de la enseñanza en el aula».

Esa preocupación por su relevancia formativa para los futuros maestros se nos antoja fundamental. Y puesto que nos interpela también a todas las áreas de conocimiento vecinas, nos ha parecido apropiado convertirla en nuestro punto de fuga valorativo. Somos conscientes de que los buenos deseos requieren de condiciones de posibilidad favorables. No lo son, desde luego, la precaria posición de la Historia de la Educación en los Grados de Magisterio y el Máster en Formación del Profesorado de Secundaria', o el hecho de que la historia del currículum, al carecer como tal de consagración legal en sus planes de estudio, tenga una presencia a lo sumo testimonial ${ }^{10}$. Pero esos escollos externos, objetivos, no

- Cfr. Goodson, I. F.: School Subjects and Curriculum Change. Case Studies in Curriculum History, London, Croom Helm, I983; Goodson, I. F.: «Patterns of Curriculum Change», en HARGreaves, A.; Lieberman, A.; Fullan, M. y Hopkins, D. (eds.): International Handbook of Educational Change, vol. I, Dordrecht, Kluwer Academic Publishers, 1998, pp. 23I-24I; o Goodson, I. F.: El cambio en el currículum, Barcelona, Octaedro, 2000.

6 VIÑAO, A.: «La historia de las disciplinas escolares», op. cit., p. 244

VV. AA.: El currículum: historia de una mediación social y cultural, op. cit., p. 7.

VIÑAO, A.: «La historia de las disciplinas escolares», op. cit., p. 269.

9 Cfr. VIÑAO, A.: «La Historia de la Educación como disciplina y campo de investigación: viejas y nuevas cuestiones», Espacio, Tiempo y Educación, 3(I) (2016), pp. 2I-42; y CANALES, A. F.; Álvarez, Y. y TAcoronte, M. ${ }^{a}$ J.: «La Historia de la Educación tras Bolonia: ¿hacia la extinción?», Revista Española de Educación Comparada, 29 (2017), pp. 240-26I.

ro $C f r$. VIÑaO, A.: «Historia de las disciplinas, profesionalización docente y formación de profesores: el caso español», Pro-Posições, 23(3) (2012), pp. I03-II8. 
nos eximen de hacer un examen de conciencia sobre la historia del currículum que realizamos de facto. Porque -trasladamos aquí la oportuna advertencia de Mateos y Mainer- ${ }^{\text {II }}$ no cualquier historia del currículum es válida por igual para la loable intención proclamada. Lo sería una historia genealógica y crítica que contribuyera a desnaturalizar «las verdades de sentido común» que los enseñantes y demás agentes implicados asumimos tácitamente acerca del currículum, mediante una suerte de distanciamiento sociogenético capaz de esclarecer los procesos que han creado y recreado las condiciones estructurales de nuestras prácticas y de nuestra propia actividad pensante. Lo sería una historia genealógica y crítica que contribuyera, en fin, a problematizar la realidad curricular actual -todo cuanto en ella se presente como dado, eterno y esencial, o como destino manifiesto e inevitable-, por la vía de desvelar su carácter históricamente construido y su significación sociopolítica subyacente. Pero si utilizamos este filtro y volvemos al esquema de Goodson, parecería que una porción llamativa de lo publicado encaja más fácilmente con el interés «académico» que con el recién apuntado.

Demos un paso más para cerrar el circunloquio. El tipo de indagación reclamado no brota simplemente al colocar el currículum bajo el foco. No sin construirlo de manera compleja como objeto de estudio. Lo cual exige «un marco teórico, flexible y revisable en el curso de la investigación -semejante al aire que se respira, en sabia expresión de Pierre Bourdieu- que actúe como marco interpretativo para permitirnos un diálogo dúctil y provechoso con las fuentes y los datos $»^{12}$. Si ponemos esta nueva capa al filtro, el panorama muestra bastantes lagunas. Hacia ellas se dirigirá este breve recorrido.

\section{Un paisaje rural con un desarrollo dual}

El 22 de septiembre de 1986 apareció en el suplemento Educación del diario El País una reseña del libro de Alberto Luis Gómez La Geografía en el Bachillerato español (1836-1970), publicado en 1985 a partir de una tesis doctoral defendida dos años antes ${ }^{13}$. El reseñista, Antonio Viñao, lo calificó de meritoria avanzadilla en estas tierras de la «sociología histórica del currículum». Para sorpresa de su autor, que no esperaba una etiqueta semejante ${ }^{\mathrm{I}}$. Si traemos a colación este dato es por un doble motivo: en primer lugar, la anécdota evoca la distancia -léxica y paradigmática- que separaba nuestra tradición académica de la anglosajona de los Estudios del Currículum; en segundo lugar, el libro mencionado marcó un hito

i Mateos, J. y Mainer, J.: «Políticas educativas e Historia de la Educación: una mirada genealógica, integradora y crítica», Paulo Freire. Revista de Pedagogía Crítica, 20 (2018), pp. 4I-67.

${ }_{12}$ Ibídem, p. 50.

${ }_{13}$ Luis Gómez, A.: La Geografía en el Bachillerato español (I836-1970), Barcelona, Publicacions i Edicions de la Universitat de Barcelona, 1985.

${ }^{14}$ Agradecemos a este egregio jubilado el amable regalo de sus recuerdos. 
e ilustra algunos rasgos característicos de un ámbito de investigación que principiaba a asomar tímidamente la cabeza.

En efecto, dejando al margen algún precedente, la historia del currículum comienza a germinar avant la lettre por estos pagos durante la década de 1980, a resultas de iniciativas aisladas y dispersas. Sintomáticamente, sus primeros cultivadores tenían una procedencia variopinta: eran docentes de enseñanzas medias, personas vinculadas a las nacientes didácticas específicas, historiadores de la educación o miembros de alguna disciplina interesados en su proyección fuera de la universidad. La práctica totalidad lanzaba una mirada al pasado de una u otra asignatura escolar concreta (geografía, historia, filosofía, literatura, matemáticas, ciencias naturales, etc. $)^{15}$, bien desde la óptica de sus contenidos, o bien, de una manera todavía más incipiente si cabe, desde la óptica de su génesis y conformación como tales asignaturas. El patrón habitual era el consagrado por las clásicas historias de la difusión de las ideas científicas y del pensamiento pedagógico. Utilizando como fuentes primordiales las regulaciones administrativas, programas escolares y libros de texto (eso que Cuesta ha llamado los «textos visibles» de la instrucción $)^{16}$, complementadas en ocasiones con las obras doctrinales de figuras afamadas y la prensa profesional coetánea, se buscaba detectar los ritmos de diseminación de las corrientes académicas en los centros de educación secundaria (y en menor medida de primaria), la mayor o menor receptividad a ciertas filosofías didácticas y las adherencias ideológicas incrustadas en unas y otras.

Con aproximaciones y alcance dispares, un porcentaje elevado de esos trabajos se centró de hecho en el análisis de los manuales escolares de un determinado período, ya fuese para evidenciar la índole arcaizante o modernizadora de sus marcos interpretativos, ya fuese para rastrear el tratamiento cambiante de ciertas temáticas, o ya fuese para sacar a la luz los valores socializadores, las narrativas legitimadoras, los sesgos adoctrinadores y los estereotipos (nacionalistas, etnocéntricos, de género y clase, religiosos) expresados y representados abiertamente o latentes en los silencios y ocultaciones. Mucho más escasos fueron los intentos por trazar el devenir general de alguna asignatura desde la implantación del sistema educativo liberal hasta el presente. Entre ellos descuella el referido de Alberto Luis Gómez, que, en opinión de Cuesta ${ }^{17}$, «bien pudiera juzgarse como la primera inserción en España del estudio de las disciplinas escolares dentro de un marco analítico relevante» ${ }^{18}$.

15 Como quedó advertido, no es nuestro propósito hacer un registro más o menos exhaustivo de la literatura generada. Tampoco sería materialmente posible en este breve artículo. Por ello debemos insistir en que nuestra lectura se apoya y descansa en los estados de la cuestión citados en la nota 3 .

16 Cuesta, R.: Sociogénesis de una disciplina escolar: la Historia, op. cit.

${ }_{17}$ Cuesta, R.: "Conocimiento e interés de la historia de las disciplinas escolares en algunos círculos fedicarianos», Con-Ciencia Social, I2 (2008), p. 136.

${ }_{18}$ Su indagación se englobaba en el ambicioso programa de investigación dirigido por Horacio Capel sobre la historia de la Geografía y su incardinación en distintas instancias sociales e institucionales, incluida la escolar. Véase, v. g. CAPEL, H. et al.: Geografía para todos. La geografía en la 
Quedaban así esbozadas en los años 80 las dos subáreas por las cuales ha transitado preferentemente, hasta nuestros días, la historiografía curricular de este país: por un lado, la manualística ${ }^{19}$, que a partir de la década siguiente experimentaría un destacado crecimiento cuantitativo y cualitativo, sobre todo tras la puesta en marcha del proyecto MANES en $1992^{20}$; por el otro, la historia de las disciplinas escolares. Sin que este comentario empañe ni un ápice el mérito (desigual) de aquellos pioneros, sus incursiones dejan entrever asimismo algunas de las flaquezas que todavía no hemos resuelto satisfactoriamente, a pesar de los innegables avances posteriores. Hablamos de la débil construcción teórica del objeto de estudio. Una debilidad que aquí se veía plasmada en una concepción demasiado elemental de las relaciones existentes entre las disciplinas académicas y las materias de enseñanza homónimas, y, a la postre, de la propia naturaleza de los saberes entregados en las aulas. Ni las asignaturas ni el conocimiento escolar (ni siquiera la parte cosificada en los libros de texto) son reducibles a un mero vehículo de algo externo a la institución educativa -una ciencia vulgarizada y miniaturizada para consumo infantil, un ideario pedagógico, los valores dominantes o contrahegemónicos de la sociedad del momento-, lastrado solo por su sempiterna tendencia a rezagarse. Como si esa institución fuese un recipiente vacío, un espacio social inerte rellenado de tal guisa. Como si la lógica interna de aquel vehículo careciese de repercusión alguna, cuando en realidad posee una función reguladora que es condición de la creación y recreación de la cultura en ese microuniverso. Contemplarlos como simples portadores de unos u otros paradigmas académicos y de representaciones ideológicas significa incurrir en una

enseñanza española durante la segunda mitad del siglo XIX, Barcelona, Los Libros de la Frontera, 1985; o Melcón, J.: La renovación de la enseñanza de la Geografía en los orígenes de la España Contemporánea, Madrid, Universidad Autónoma de Madrid, 1995.

19 Cfr. Escolano, A.: «Sobre la construcción histórica de la manualística en España», Revista Educación y Pedagogía, vol. I3, n. ${ }^{\circ}$ 29-30 (200I), pp. II-24.

${ }_{20}$ A imagen y semejanza del proyecto francés EMmanuelle, MANEs nació con el objetivo principal de investigar los manuales escolares producidos en España, Portugal y América Latina durante los siglos XIX y XX. Esta magna empresa interuniversitaria -más tarde reconvertida en centro de investigación, con sede en la Universidad Nacional de Educación a Distancia- ha tenido una actividad intensa, reflejada en su página web (http://www.centromanes.org) y en varias recapitulaciones (v. g. Tiana, A.: «Los manuales escolares», en Guereña, J.-L.; Ruiz Berrio, J. y TianA, A. [eds.]: Nuevas miradas historiográficas sobre la educación en la España de los siglos XIX y XX, Madrid, Ministerio de Educación, Cultura y Deporte, 20IO, pp. 2II-230). Sin olvidar otras publicaciones surgidas bajo su paraguas, la colección del mismo nombre, iniciada en 1997 y ya próxima a la veintena de libros (véase http://www.centromanes.org/?page_id=9897), constituye sin duda una referencia ineludible. Por supuesto, ha habido vida para la manualística fuera de MANEs. Para muestra, un par de botones: la Fundación Germán Sánchez Ruipérez, instituida en 1981 por el fundador de la editorial de libros de texto Anaya, ha patrocinado un abanico de obras, entre ellas los dos tomos de la espléndida Historia ilustrada del libro escolar en España dirigida por A. Escolano en 1997 y 1998. Por su parte, las actividades del Centro Internacional de la Cultura Escolar (CEINCE) -una entidad ubicada en Berlanga de Duero (Soria) y dirigida por el catedrático jubilado recién mentado (véase https://www. ceince.eu)- han originado frutos de interés como Escolano, A. (ed.): Currículum editado y sociedad del conocimiento. Texto, multimedialidad y cultura de la escuela, Valencia, Tirant Lo Blanch, 2006. 
cuasi-redundancia que nos deja en la superficie del currículum sin informar demasiado sobre su textura y dinámica.

Cierto es que, a partir de la década de 1990, se fabricaron condiciones propicias para una profunda renovación conceptual, gracias a la propagación de las líneas de trabajo más potentes -por su estrecho diálogo con la teoría social- del panorama internacional. Cierto es que en ese decenio la tribu de los historiadores de la educación sentó oficialmente sus reales en esta campa, y ello coadyuvó al crecimiento de su hasta entonces magra producción. El problema, como intentaremos demostrar, es que ese doble impulso (propagador y productor) semeja una vía de tren inestable, con dos raíles paralelos y escasas traviesas a modo de nexos o puntos de intersección.

\section{I. El acicate foráneo}

Se ha destacado con justicia el hito que supuso la publicación en I99I, por parte de la Revista de Educación, de dos números monográficos (el 295 y el 296) dedicados a la historia del currículum, merced a los buenos oficios de quien ha sido su principal divulgador en España, Miguel Á. Pereyra, a la sazón secretario entre 1986 y 1992 de esta revista editada por el Ministerio de Educación y Ciencia. En otros escritos $^{21}$ hemos relatado los pormenores de su labor al respecto, en realidad iniciada ya, en lo que al tema de nuestra incumbencia se refiere, con anterioridad. Sin ir más lejos, baste recordar el monográfico sobre teoría curricular aparecido cuatro años antes en el número 282 de la misma revista. Entre otros, cobijaba sendos artículos de Jean-Claude Forquin, Cleo H. Cherryholmes y Thomas S. Popkewitz que servían como puerta de entrada a la nueva sociología del conocimiento escolar británica y norteamericana. Pero volvamos a los dos números de 1991. Lo reseñable no es solo la impresionante lista de primeros espadas europeos y norteamericanos traducidos al castellano, sino también la vocación y el alcance general de ambos volúmenes. El breve preámbulo firmado por Pereyra expresaba la necesidad de -e invitaba a- nuevas formas de historiar, al presentar el conjunto de artículos como ilustraciones elocuentes de los marcos de comprensión enriquecidos que estaba deparando un cuerpo de investigación histórica emergente, abierta a otras ciencias sociales y a la teoría social. De manera similar, se invitaba igualmente a trascender los temas acostumbrados. Valga el siguiente punto de referencia para captar lo ambicioso del empeño. En su colaboración a la segunda edición de la International Encyclopedia of Education coordinada por Husén y

2r Véase Luis, A. y Romero, J.: «De la Pedagogía a la Teoría Social: la voz de Miguel Á. Pereyra y su escaso eco institucional entre los historiadores españoles de la educación», Con-Ciencia Social, Io (2006), pp. 85-IO3; y Romero, J. y Luis, A.: «La experiencia del viaje. Una conversación con Miguel Á. Pereyra», Con-Ciencia Social, Io (2006), pp. I05-I28. 
Postlethwaite, Gundem ${ }^{22}$ distinguía cinco grandes parcelas dentro de la historia del currículum:

a) La historia de los movimientos y de las tradiciones curriculares, enraizada en la clásica historia del pensamiento educativo, pero de más altos vuelos analíticos, tal como demostraban los trabajos de Herbert M. Kliebard y Barry M. Franklin sobre los enfrentamientos, componendas y transacciones entre los grupos de presión que habían determinado el currículum en Estados Unidos, o de Peter Cunningham sobre la atribulada irradiación de los ideales de la new education en el currículum de la escuela primaria inglesa. Pues bien, el número 295 acogía un estado de la cuestión de Franklin.

b) La historia de los códigos curriculares. El epígrafe trae a las mientes de manera inmediata el nombre de Ulf P. Lundgren, quizá el representante más eminente de una corriente historiográfica asentada desde la década de 1980 en los países escandinavos, al calor del influjo de la nueva sociología y de Basil Bernstein. Sobre esa corriente daba cumplida cuenta el artículo de Tomas Englund en el mismo número. Aunque sus ascendientes teóricos eran otros, también podría englobarse bajo este epígrafe el de Abram de Swaan, un enjundioso estudio de historia comparada sobre el currículum elemental como "código nacional de comunicación».

c) La historia de las disciplinas escolares. El número 295 incluía dos textos capitales de Ivor F. Goodson y André Chervel, máximos exponentes de las entonces flamantes historia social británica e historia cultural francesa de las materias de enseñanza. Junto a ellos podía leerse uno de Aaron Benavot et al. que nos introducía en el vasto programa de investigación internacional sobre la estandarización de los planes de estudio a escala planetaria, en la línea de la sociología histórica comparada de raigambre neoinstitucionalista, liderado desde la Universidad de Stanford por John W. Meyer y Francisco O. Ramírez.

d) La historia de las políticas y reformas curriculares. Investigaciones tempranas como The Myth of Educational Reform, dada a luz en 1982 por Popkewitz, Tabachnik y Wehlage, habían evidenciado el carácter sumamente complejo y contradictorio de las reformas y, en general, de los procesos sociales de control del currículum, imposibles de aprehender con el mero escrutinio de las sucesivas directrices gubernamentales. Los artículos de los alemanes Heinz-Elmar Tenorth y Stefan Hopmann y del islandés Ingolfur A. Johannesson, repartidos en los números 295 y 296, se adentraban en esa complejidad contradictoria.

e) La bistoria de las prácticas curriculares. La revisión ya citada de Franklin daba cancha, por ejemplo, a una acreditada indagación de Larry Cuban -How Teachers Taught: Constancy and Change in American Classrooms, I890-I980, publicada en 1984- sobre la perduración de inveteradas inercias

22 Gundem, B. B.: «History of curriculum», en Husén, T. y Postlethwaite, T. N. (eds.): The International Encyclopedia of Education, 2. ${ }^{a}$ ed., vol. 3, Oxford, Pergamon, 1994, pp. I30I-I308. 
enquistadas en la cotidianidad del aula, a despecho de las múltiples aventuras reformistas emprendidas a lo largo de la pasada centuria.

A modo de complemento, algunas contribuciones como la de David Hamilton y Harold Silver abordaban problemas relativos a la conceptualización o a la finalidad del ejercicio historiográfico-curricular. En suma, ambos números eran un expositor privilegiado de la vanguardia del campo. En este sentido, la mano de Pereyra se deja notar en la organización del IX Coloquio de Historia de la Educación, celebrado en 1996 en Granada: la conferencia inaugural la pronunció Barry Franklin, el prólogo que abre el libro de actas reproduce, casi literalmente, la introducción de los monográficos de Revista de Educación, y los grupos de trabajo dispuestos abarcan nominalmente buena parte de las temáticas enumeradas.

Pero su labor de difusión no acabó ahí. Bajo su inspiración y dirección se lanza en 1994 la colección Educación y Conocimiento en la editorial Pomares-Corredor, que se ha ido alimentando con libros de enorme relevancia para nuestro objeto: Historia del currículum. La construcción social de las disciplinas escolares, de Ivor F. Goodson (1995); Libros de texto en el calidoscopio. Estudio crítico de la literatura y la investigación sobre los textos escolares, de Egil Børre Johnsen (1996); Sociogénesis de una disciplina escolar: la Historia, de Raimundo Cuesta (1997), a nuestro juicio la obra cumbre de la historiografía española sobre las materias de enseñanza; Historia Patria. Política, historia e identidad nacional en España, 1875I975, de Carolyn P. Boyd (2000); Historia cultural y educación. Ensayos críticos sobre conocimiento y escolarización, compilado por Thomas S. Popkewitz, Barry M. Franklin y Miguel Á. Pereyra (2003); ¿Qué es la teoría del currículum?, de William F. Pinar (2006), etc. En I998 puso en marcha, con la codirección de Ian Westbury, la Revista de Estudios del Currículum (REC), en cuyos números se traducía una cuidada selección de artículos publicados en el Journal of Curriculum Studies con el suplemento de uno o dos más de autores hispanoamericanos. $R E C$ tuvo una corta existencia, pero suficiente para gestar sendos monográficos sobre teoría del currículum, política educativa y reforma del currículum e historia del currículum. En 2008 arrancó bajo su dirección la serie Educación Comparada e Internacional en la editorial Octaedro, en cuyo catálogo figura una obra de Meyer y Ramírez que recopila lo más granado de las investigaciones neoinstitucionalistas del currículum en la «sociedad mundial» acometidas por la Escuela de Stanford o de Daniel Tröhler, crítico con dicha perspectiva neoinstitucionalista $\mathrm{y}$ atento a las idiosincrasias culturales de los «lenguajes» o cosmovisiones educativas latentes. Su papel fue crucial en el monográfico que la revista Profesorado dedicó en 2007 a la historia social del currículum, con aportaciones de Popkewitz, Franklin y Johnson, Gustafson y Tröhler, etc.

Excusa decir que la acción divulgadora de los vientos foráneos no se ha restringido a Pereyra. Por ceñirnos al gremio de historiadores de la educación, recuérdese, verbigracia, el eminente capítulo de Dominique Julia sobre la génesis de las disciplinas escolares -desde la perspectiva de la historia de la cultura escolar cultivada en Francia- que se añadió a un volumen colectivo coordinado por Julio 
Ruiz Berrio ${ }^{23}$; los estados de la cuestión de Antonio Viñao y Mariano González Delgado $^{24}$, o el espacio concedido en las revistas Historia de la Educación e Historia y Memoria de la Educación a autores de la talla de Alain Choppin, Tröhler, Popkewitz, Peter Cunningham o Goodson. Pero lo que queremos destacar es lo siguiente: desde el punto de vista de la circulación de los enfoques teóricos y metodológicos punteros a nivel internacional, no podemos quejarnos. No han faltado estímulos para repensar, tomar en préstamo, debatir y, en definitiva, mejorar las herramientas heurísticas empleadas.

\subsection{La producción local}

En un artículo datado en 20I2, Antonio Viñao ${ }^{25}$ lamentaba «el escaso desarrollo de la investigación sobre la historia de las disciplinas», una valoración extensible a la historia del currículum en su globalidad. Para sostener esta afirmación, calculó la presencia porcentual de esta temática en las principales revistas españolas de Historia de la Educación, Historia de la Ciencia, Didáctica general y Didácticas específicas, considerando el total de artículos publicados en ellas en el período 2000-2009. Distorsionaba la imagen resultante al alza la revista Con-Ciencia Social, editada por la Federación Icaria (Fedicaria), por razones que se atisbarán más adelante. En las revistas Llull-dedicada a la historia de la ciencia- e Historia de la Educación los porcentajes llegaban al I8,95 \% y I5,40 \% respectivamente. Alcanzaba el го,8г \% en Didáctica de las Ciencias Experimentales y Sociales y oscilaba entre el o,6 \% y el $5 \%$ en todas las demás. Las cifras cobraban su verdadera magnitud cuando se reparaba en que una porción substancial de trabajos se acercaba a este objeto desde la óptica exclusiva de los libros de texto. No en vano, concluía Viñao ${ }^{26}$, «uno de los rasgos que [...] caracterizan la historiografía española sobre las disciplinas escolares [es que] su desarrollo en los últimos años ha tenido lugar en buena parte dentro y a partir de los estudios sobre la historia de los manuales escolares». Por añadidura, y el dato era revelador, ninguna de las

${ }^{23}$ Julia, D.: «Construcción de las disciplinas escolares en Europa», en Ruiz Berrio, J. (ed.): La cultura escolar de Europa. Tendencias históricas emergentes, Madrid, Biblioteca Nueva, 2000, pp. 45-78.

${ }_{24}$ GonzÁlez Delgado, M.: «La historia del currículum en EE. UU. y Gran Bretaña. Una revisión historiográfica y algunas aportaciones teóricas y metodológicas para el contexto español», Historia de la Educación, 32 (2013), pp. 315-342; GonzÁlez Delgado, M. y Woyshner, C.: «Historia del currículum y nuevas tendencias de investigación: un panorama nacional e internacional», Espacio, Tiempo y Educación, 4(2) (2017), pp. i-I8; McCulloch, G.; Goodson, I. y GonZÁlez Delgado, M.: «Curriculum history and transnational perspectives for studies: Generating debates on educational research», en McCulloch, G.; Goodson, I. y González Delgado, M. (eds.): Transnational Perspectives on Curriculum History, London, Routledge, 2020, pp. I-II.

${ }_{25}$ VIÑAO, A.: «Historia de las disciplinas, profesionalización docente y formación de profesores: el caso español», op. cit., p. 107.

${ }_{26}$ Ibídem, p. IIз. 
revistas revisadas le había concedido un número monográfico a este asunto, ni en ese lapso temporal ni con anterioridad.

El panorama apenas ha cambiado. Dentro de las revistas histórico-educativas se encuentra algún monográfico aislado sobre libros de texto, pero solo Espacio, Tiempo y Educación dedicó uno en fechas recientes a las «nuevas direcciones y perspectivas en Historia del Currículum ${ }^{27}$, con escasa presencia de firmas españolas. Para actualizar parcialmente las estadísticas de Viñao, hemos vaciado las dos revistas más emblemáticas del gremio, Historia de la Educación e Historia y Memoria de la Educación, sucesivos órganos de comunicación científica de la Sociedad Española de Historia de la Educación (SEDHE): la primera desde su nacimiento en 1982 hasta 2010, y la segunda desde su presentación en sociedad en 20I5. De la una hemos explorado los 36 volúmenes que han salido a la calle entre 1982 y 20I8. Y de la otra los 9 números alumbrados entre 2015 y 20I9. En ambos casos con la intención de computar la proporción de artículos «encuadrables» en la historia del currículum ${ }^{28}$ sobre el total publicado. Los resultados se reflejan en esta tabla de frecuencias.

\begin{tabular}{|c|c|c|c|c|}
\hline \multicolumn{5}{|c|}{ Revista Historia de la Educación (1982-2018) } \\
\hline $\mathrm{N}^{\text {I }}$ & $\mathrm{HC} f_{\mathrm{i}}^{2}$ & $\mathrm{HC}_{\mathrm{i}} / \mathrm{N}^{3}$ & $\mathrm{M} \subset \mathrm{HC} f_{\mathrm{i}}{ }^{4}$ & $\mathrm{M} \subset \mathrm{HC} f_{\mathrm{i}} / \mathrm{HC} f_{\mathrm{i}}{ }^{s}$ \\
\hline 562 & 57 & IO,I4 \% & I8 & $31,6 \%$ \\
\hline \multicolumn{5}{|c|}{ Revista Historia y Memoria de la Educación (2015-2019) } \\
\hline II7 & 25 & $2 \mathrm{I}, 37 \%$ & I8 & $72 \%$ \\
\hline
\end{tabular}

Leyenda:

${ }^{1} \mathrm{~N}=$ Total de artículos publicados en las secciones «Monografía» $\mathrm{y}$ «Estudios» (Historia de la Educación) y «Monografía» e «Investigaciones históricas» (Historia y Memoria de la Educación).

${ }^{2} \mathrm{HC} f_{\mathrm{i}}=$ Frecuencia absoluta de artículos directamente entroncados con la historia del currículum.

${ }^{3} \mathrm{HC} f_{\mathrm{i}} / \mathrm{N}=$ Porcentaje representado por los artículos de historia del currículum sobre el total.

${ }^{4} \mathrm{M} \subset \mathrm{HC} f_{\mathrm{i}}=$ Subconjunto de artículos de historia del currículum centrados en el análisis de manuales escolares, en cifras absolutas.

s $\mathrm{M} \subset \mathrm{HC} f_{\mathrm{i}} / \mathrm{HC} f_{\mathrm{i}}=$ Porcentaje representado por los artículos que analizan manuales escolares sobre el número de artículos de historia del currículum

Como se verá, solo 57 de los 562 artículos aparecidos en Historia de la Educación (un IO,I4 \%) tienen relación directa con la historia del currículum, y, de ellos, casi un tercio responden al género de la manualística. La corta vida de Historia

27 En el volumen 4, número 2 (2017), bajo la coordinación de Mariano González Delgado y Christine Woyshner.

${ }_{28}$ Como cabía esperar, no siempre es fácil atribuir etiquetas. Nosotros hemos contabilizado aquellos con una relación razonablemente directa con este ámbito. 
LA HISTORIA DEL CURRÍCULUM EN ESPAÑA:

LA RURALIDAD DUAL DE UN SUBCAMPO TODAVÍA EN CONSTRUCCIÓN

JESÚS ROMERO MORANTE Y MARTA ESTELLÉS FRADE

y Memoria de la Educación, sumada al hecho de que uno de los monográficos versó sobre «enseñanza de la Historia, análisis de libros de texto y construcción de identidades colectivas», explica que el porcentaje sea aquí mayor (un 2I,37 \%). Pero casi tres cuartas partes de esos artículos responden nuevamente al género de la manualística.

Añadamos un indicador más. Una colección editorial asimismo emblemática es Memoria y Crítica de la Educación, dirigida por Agustín Escolano en Biblioteca Nueva. Según su catálogo ${ }^{29}$, actualizado a I9 de noviembre de 20I8, la serie Monografías de dicha colección llegaba a los 28 títulos. En sentido estricto, solo un par de ellos son historiográfico curriculares ${ }^{30}$, aunque el currículum tenga un peso importante en algún otro ${ }^{31}$. Sin duda, estas son imágenes fragmentarias, pero indicativas al fin y al cabo de la «ruralidad» de este subcampo. Sin embargo, no es su densidad de población comparativamente baja lo que nos preocupa, sino su nivel de desarrollo. Y a este respecto algunas evidencias sí se nos antojan inquietantes.

El mero repaso al contenido de la revista Historia de la Educación a lo largo de sus 37 años de existencia es suficiente para advertir la innegable renovación experimentada por la investigación histórico-educativa hispana en las últimas cuatro décadas. No obstante, esta constatación parece tener en la historia del currículum una excepción parcial. Por descontado, el bagaje empírico acumulado ha aumentado de manera considerable. Pero los marcos conceptuales desde los cuales se problematiza e interroga el objeto de estudio no han avanzado a la par en amplias zonas de nuestro paisaje rural. Sirvan de prueba los siguientes datos. De los 57 artículos identificados en esta revista, solo i7 (el 29,8 \%) maneja alguna bibliografía internacional representativa de la nueva historia del currículum o de la historiografía nativa más influida por ella, aunque a veces las citas son meramente informativas o adornos discursivos sin ningún sentido heurístico. De esos I7, únicamente 7 (I2,28 \%) se hacen eco de los dos monográficos de I991 de la Revista de Educación y apenas $3(5,36 \%)$ dialogan con la sociología del conocimiento

29 Puede consultarse en http://www.bibliotecanueva.es.

30 Nos referimos a los trabajos de Del Pozo, M. ${ }^{a}$ M.: Currículum e identidad nacional. Regeneracionismos, nacionalismos y escuela pública (1890-1939), Madrid, Biblioteca Nueva, 2000; y de Bernal, J. M.: Renovación pedagógica y enseñanza de las Ciencias. Medio siglo de propuestas y experiencias escolares (I882-I936), Madrid, Biblioteca Nueva, 200I.

${ }_{31}$ Hemos citado ya el editado por Ruiz Berrio (véase la nota 23), y podríamos agregar alguno más, empezando por el iluminador libro de Escolano, A.: Tiempos y espacios para la escuela. Ensayos históricos, Madrid, Biblioteca Nueva, 2000. Salvo que ensanchemos el término «currículum» hasta abarcar toda la organización escolar -y no faltarían argumentos, pues en sí misma es una «forma silenciosa de enseñanza», en palabras de G. Mesmin reproducidas por TERrón, A.: «Cuando los historiadores de la educación aterrizan en el currículum», Con-Ciencia Social, 6 (2002), p. II2-, no hemos considerado que los muy interesantes estudios sobre tiempos y espacios escolares realizados en este país sean per se historia del currículum, a menos que esos y otros elementos clave del ordenamiento y funcionamiento institucionales se analicen como reactivos de la transmutación que convierte una determinada selección cultural, unos saberes científicos, en conocimientos sui géneris para uso escolar. Un análisis, dicho sea de paso, absolutamente necesario e imprescindible para cualquier observador del currículum, tal como se defenderá en el próximo apartado. 
escolar. En el caso de la revista Historia y Memoria de la Educación, los porcentajes para el primer y último capítulo serían el $28 \%$ y el I6 \% respectivamente.

Resulta revelador contemplar bajo este prisma los libros de actas de los dos Coloquios Nacionales de la SEDHE que dieron carta de naturaleza simbólica a esta especialidad dentro del gremio. En el ya mencionado de 1996 en Granada, de las 93 comunicaciones repartidas en las secciones relacionadas, el reflejo-siquiera retórico- de la nueva historia y de la sociología del currículum se ve apenas en el I0,75 \% y el 4,30 \% respectivamente. En el caso del XI Coloquio ${ }^{32}$, celebrado en Oviedo en 200 bajo el lema «La acreditación de saberes y competencias. Perspectiva histórica», esos porcentajes se sitúan en el I5,22 \% y el 4,35\%.

En suma, se han multiplicado las indagaciones y las miradas, se manejan más y distintas fuentes, se han refinado algunos métodos, pero, al tiempo de construir teóricamente el objeto de estudio (de no hacerlo, en realidad), se mantienen las viejas carencias. Desde ese punto de vista, cabría aseverar -continuando con la metáfora geográfica de Becher- que el territorio ha experimentado un desarrollo dual: grandes áreas de secano con una utilización extensiva o nula de «capital conceptual» y algunas islas de regadíos intensivos, mejor integradas -en su notoria heterogeneidad- en la «economía teórico-curricular» internacional.

\subsection{La agricultura intensiva}

Sin ninguna sistematicidad, pasaremos revista a varios «regadíos» que merecen ser visitados. Empecemos por los trabajos de Antonio Viñao y el conjunto de investigaciones sobre disciplinas escolares realizadas a su vera en la Universidad de Murcia. Con una maleta bien pertrechada de herramientas intelectuales, en las que se acusa de un modo especial el ascendiente de la historiografía educativo-cultural francesa, Viñao se ha acercado al asunto que nos incumbe partiendo de distintas estaciones: desde el análisis de los espacios y tiempos escolares ha llegado a la graduación y segmentación vertical y horizontal del currículum ${ }^{33}$; desde la génesis de los cuerpos de profesores estatales se ha asomado a la historia de la construcción social de las disciplinas ${ }^{34}$; y desde la cultura de la escuela, a la incierta suerte de reformas e innovaciones ${ }^{35}$. Bajo su dirección se pusieron en marcha una

32 VV. AA.: La acreditación de saberes y competencias. Perspectiva histórica, XI Coloquio Nacional de Historia de la Educación, Oviedo, SEDHE/Universidad de Oviedo, 2oor.

33 VIÑAO, A.: Innovación pedagógica y racionalidad científica. La escuela graduada pública en España (I898-1936), Madrid, Akal, I990; VIÑAO, A.: Tiempos escolares, tiempos sociales. La distribución del tiempo y del trabajo en la enseñanza primaria en España (1838-1936), Barcelona, Ariel, 1998.

34 VIÑAO, A.: «Disciplinas académicas y profesionalización docente: los Reales Estudios de San Isidro (1770-I808)», en GUEREÑA, J.-L. y FELL, E.-M. ${ }^{a}$ (eds.): L'université en Espagne et en Amérique Latine du Moyen Âge à nos jours. II. Enjueux, contents, images, Tours, Publications de l'Université de Tours, 1998, pp. 303-323.

35 VIÑaO, A.: Sistemas educativos, culturas escolares y reformas. Continuidades y cambios, Madrid, Morata, 2002. 
decena de tesis doctorales sobre la historia de la enseñanza de distintas materias, defendidas entre 1991 y 2015. Las que hemos tenido la fortuna de leer tras su publicación ${ }^{36}$ se sirven de la literatura anglosajona y francesa, aunque de manera un tanto paradójica.

La obra de Agustín Escolano, uno de los máximos exponentes peninsulares del giro hacia esta suerte de historia antropológica volcada en la cultura material e inmaterial de la escuela, es otra parada obligada. Desde la Universidad de Valladolid ha hecho contribuciones enjundiosas -en las cuales no falta la interpelación a la teoría social- para entender tanto la refracción sufrida en las escuelas por tantos planes de mejora de la instrucción, que explica a partir de los desencuentros entre la cultura científica de los expertos universitarios, la burocrática de las administraciones y la «empírica» de los maestros ${ }^{37}$, como la práctica curricular «artesanal» de estos últimos ${ }^{38}$. La huella francesa, sobre todo la de Chervel, se deja sentir igualmente en las sólidas pesquisas de Aida Terrón en la Universidad de Oviedo ${ }^{39}$. A bastante distancia física y generacional, Mariano González Delgado ha buceado con empeño en la bibliografía anglosajona desde la Universidad de La Laguna ${ }^{40} \ldots$

No obstante, el regadío más frondoso ha crecido fuera de las fronteras de esa tribu académica, e incluso de la propia Academia. Dentro de Fedicaria. Al decir de Viñao ${ }^{41}$, «en su seno, y en especial dentro del proyecto Nebraska y del grupo Asklepios, se han venido elaborando toda una serie de conceptos y categorías de análisis general sobre la historia de las disciplinas escolares que, con independen-

36 Bernal, J. M.: Renovación pedagógica y enseñanza de las Ciencias. Medio siglo de propuestas y experiencias escolares (I882-1936), op. cit.; CARRILlo, D.: La Metodología de la aritmética en los comienzos de las Escuelas Normales (1838-1868) y sus antecedentes, Murcia, Departamento de Didáctica de las Ciencias Matemáticas y Sociales de la Universidad de Murcia, 2005.

37 Escolano, A.: «Las culturas escolares del siglo. Encuentros y desencuentros», Revista de Educación, n. ${ }^{\circ}$ extraordinario (2000), pp. 20I-2I8.

${ }_{38}$ Véase, por ejemplo, su último libro: Escolano, A.: La escuela como cultura. Experiencia, memoria y arqueología, Campinas, Alínea Editorial, 2017.

39 V. g. Terrón, A. y Alonso, P.: «La historia de las disciplinas escolares, una contribución esencial al conocimiento de la escuela. El caso de la Aritmética», Revista Complutense de Educación, vol. IO, n. ${ }^{\circ}$ I (1999), pp. 305-333; TERrón, A.: «Los exámenes escolares y el tempo de las disciplinas», en VV. AA.: La acreditación de saberes y competencias. Perspectiva histórica, XI Coloquio Nacional de Historia de la Educación, Oviedo, SEDHE/Universidad de Oviedo, 20oI, pp. 5II-524; TERrón, A.: «La educación sanitaria escolar, una propuesta curricular importada para la escuela española del desarrollismo", Archivos Analiticos de Políticas Educativas, 23(19) (2015), pp. I-3o.

40 Como prueban su tesis doctoral (González Delgado, M.: Conflicto, legitimación y cambio en el currículum: 1970-1990, La Laguna, Servicio de Publicaciones de la Universidad de La Laguna, 20I4) o sus incursiones en la política curricular bajo el franquismo: v. g., GonZÁlez Delgado, M. y GROVES, T.: «La enseñanza programada, la UNESCO y los intentos por modificar el currículum en la España desarrollista (1962-I974)», Espacio, Tiempo y Educación, 4(2) (2017), pp. I2I-I42; GonZÁLEZ Delgado, M. y Groves, T.: «UNESCO mediation in Francoist curriculum policy: The case of educational television in Spain», en McCulloch, G.; Goodson, I. y GonZÁlez Delgado, M. (eds.): Transnational Perspectives on Curriculum History, op. cit., pp. 83-I07.

${ }_{41}$ VIÑAO, A.: «La historia de las disciplinas escolares», op. cit., p. 258. 
cia del acuerdo o desacuerdo con las mismas, constituyen hoy en día el marco teórico y la aportación colectiva más coherente y estructurada sobre el particular que existe en España». A fuer de justos, el destinatario de semejante elogio es, ante todo, Raimundo Cuesta Fernández, un profesor de instituto cuya tesis doctoral sobre la invención y construcción social de la Historia como disciplina escolar, en el contexto de la implantación y expansión del sistema educativo nacional y con el trasfondo de las transformaciones socioeconómicas, políticas e ideológicas de la España contemporánea, ha marcado un antes y un después en este país ${ }^{42}$. En primer lugar, por la brillantez de una investigación que se adentra con agudo bisturí no solo en las regulaciones ministeriales, los programas y los manuales, o en los anhelos de innovadores y reformistas de toda laya, sino también en los espacios y tiempos escolares, en las redes de saber y poder profesionales, y en el mundo de las prácticas reales de aula, haciendo uso de una amplísima gama de fuentes. Una investigación, por cierto, que ha demostrado fehacientemente que la historia de las disciplinas científicas y de las escolares, estando relacionadas, son sin embargo distintas. Las segundas no son meras adaptaciones o imitaciones, sino entes culturales idiosincrásicos, hasta el punto de que ciertos ritos y mitos, vistos todavía hoy por muchos como el reflejo obvio de la «esencia» epistemológica de la disciplina académica, se inventaron y comenzaron a convertirse en tradición duradera antes de la propia constitución y profesionalización de la ciencia histórica.

En segundo lugar, y sobre todo, por la enorme potencialidad de sus herramientas heurísticas. A partir de un humus fertilizado por la historiografía de las asignaturas inglesa y francesa, la teoría del currículum, la sociología crítica del conocimiento escolar y de la educación, amén de otros referentes teórico-sociales, como Foucault y Bourdieu, Cuesta elaboró un arsenal conceptual original (código disciplinar, campo profesional, modo de educación) ${ }^{43}$ que ha tenido un impacto apreciable en España y Latinoamérica. De entrada, en el interior de Fedicaria, donde sirvió de inspiración al Proyecto Nebraska, que ha generado investigaciones tan relevantes como la de Javier Merchán sobre la recreación y creación cotidiana del código disciplinar de la Historia a través de las actuaciones de profesores y alumnos en los institutos de secundaria ${ }^{44}$, la de Juan Mainer sobre el nacimiento del campo profesional de los didactas de las Ciencias Sociales ${ }^{45} \mathrm{O}$ la de Julio Mateos sobre la genealogía del código de una materia no disciplinar

${ }^{42}$ Dicha tesis se publicó desglosada en dos libros: CuestA, R.: Sociogénesis de una disciplina escolar: la Historia, op. cit.; y CUESTA, R.: Clío en las aulas. La enseñanza de la Historia en España entre reformas, ilusiones y rutinas, Madrid, Akal, 1998.

${ }_{43}$ Para una aclaración, véase el artículo firmado por este autor en este mismo monográfico.

${ }_{44}$ Merchán, F. J.: Enseñanza, examen y control. Profesores y alumnos en la clase de Historia, Barcelona, Octaedro, 2005.

45 Mainer, J.: La forja de un campo profesional. Pedagogía y didáctica de las ciencias sociales en España, 1900-1970, Madrid, CSIC, 2009. 
derivada de la pedagogía del entorno ${ }^{46}$. También las indagaciones sociogenéticas del grupo Asklepios en la Universidad de Cantabria ${ }^{47}$ se han beneficiado de este influjo, aunque no hayamos sido capaces de aprovechar toda su riqueza.

Al margen de los círculos fedicarianos, las categorías analíticas mencionadas han encontrado eco entre los historiadores de la educación, y han sido un factor inductor de un mínimo debate teórico. Incluso alguno -nos referimos a Mariano González Delgado- ha pretendido esbozar una «teoría sobre la historia del currículum» (sic) a partir de su discusión revisionista. Precisamente por ello utilizaremos sus críticas como excusa para cerrar este artículo allí donde anunciamos. No por las críticas en sí -cualquier herramienta heurística está, y debe estar, abierta siempre a escrutinio y revisión-, sino por lo que asumen acerca de la naturaleza y dinámica del currículum. Tales asunciones son, en nuestra opinión, muy expresivas de algunos problemas de concepto que siguen lastrando a una parte de la historiografía curricular española, entorpeciendo por añadidura su capacidad de entregar esa historia más pertinente para los docentes que se prometía.

\section{De tribulaciones teóricas y sus consecuencias prácticas}

Mezclando indistintamente los planteamientos de Cuesta y los de Viñao, González Delgado ${ }^{48}$ ha cuestionado el valor heurístico de categorías analíticas como código disciplinar, campo profesional, cultura escolar, subculturas de asignatura o gramática de la instrucción para dar cuenta de la continuidad y el cambio curriculares. En un primer artículo de 2008 calca llamativamente, quizá sin advertirlo, el mismo argumentario esgrimido por John Rex y otros teóricos del conflicto contra Parsons a inicios de la década de 1960. Lo cual le ha obligado a desfigurar a sus interlocutores hasta exhibirlos como funcionalistas que retratan las asignaturas, y el «orden» escolar que las sostiene, en clave de una estabilidad a prueba de alteraciones, inmune a presiones externas (e internas), realimentada a través de una socialización profesional totalizadora que termina generando un asfixiante consenso normativo legitimador. Un esquema tal excluiría «la conside-

${ }_{46}$ Mateos, J.: Genealogía de un saber escolar: el código pedagógico del entorno, Barcelona, Octaedro, 20II.

47 V.g. Luis, A. y Romero, J.: Escuela para todos, conocimiento académico y geografía escolar en España (I830-1953), Santander, Universidad de Cantabria, 2007; Romero, J. y EsTEllés, M.: «Governmentality, Curriculum Policies, and Citizenship Education: The Need for Historical Research», en Pineda, J. A.; De Alba, N. y Navarro, E. (eds.): Handbook of Research on Education for Participative Citizenship and Global Prosperity, Hershey PA, IGI Global, 2019, pp. 274-30I.

${ }_{48}$ GonzÁlez Delgado, M.: «Notas para una evaluación de la historia del currículum: estudio de los procesos de legitimación y cambio», Tempora, II (2008), pp. 97-I34; GonZÁlez Delgado, M.: «Continuidades y cambios en las disciplinas escolares: apuntes para una teoría sobre la historia del currículum», Education in the Knowledge Society (EKS), vol. I5, n. ${ }^{\circ} 4$ (2014), pp. 262-294; GONZÁLEZ Delgado, M. y Ferraz Lorenzo, M.: «Factores determinantes de las disciplinas escolares: esbozo para un nuevo enfoque de la historia del currículum», en Actas del XVIII Coloquio de Historia de la Educación: Arte, literatura y educación, vol. 2, Vic, Universitat de Vic, 20I5, pp. 487-498. 
rable libertad del profesorado para aplicar una forma de enseñar en función de su ideología»49; el disenso, inherente a la pluralidad de metas e intereses de los docentes y demás actores implicados; el poder configurador de la política educativa y del currículum que pueden llegar a detentar grupos externos; y, a la postre, el cambio. A la vista de semejantes inconsistencias de la «perspectiva del orden», la solución estaría en la «perspectiva del conflicto». En los escritos posteriores ha matizado las pinceladas más gruesas, pero llega a idéntico puerto: el currículum sería el resultado contingente, y en continua redefinición, de los acuerdos precarios que zanjan temporalmente los conflictos y luchas entre profesores y sus eventuales alianzas con sectores de la colectividad.

Los dardos de González Delgado contra algunas concepciones hipostasiadas y autorreferenciales de la noción de «cultura escolar» son pertinentes y oportunos, aunque creemos que confunde el destinatario. Es de agradecer, asimismo, su esfuerzo teorizador, bastante insólito en su tribu. Sin embargo, malinterpreta la cuestión de fondo y sus derroteros le acaban llevando, paradójicamente, al mismo lugar del que nunca se movió buena parte de la historiografía española: ese donde se persiste en adoptar un punto de vista «externo» con respecto al currículum. Por supuesto, la escuela como institución social y el currículum en tanto que selección arbitraria de cultura modulada por unas líneas de inclusión y exclusión son espacios donde se reflejan y desdoblan las luchas simbólicas coetáneas y una diversidad de intereses sociales. Son, siempre lo han sido, campos de fuerzas en tensión. Pero si reducimos las materias instructivas a simples cintas transportadoras, reajustables a voluntad, que se limitan a trasladar «lo que llega desde el exterior» en cada momento o las componendas que se van alcanzando en las conflictivas micro- y macrorrelaciones de poder, lo que estaremos haciendo es fijarnos en el equipaje y dar por sentado el vehículo o dispositivo pedagógico que permite su traslado.

La principal herencia que dejó la nueva sociología del conocimiento escolar de los años 70, sobre la que se ha edificado la mejor historia del currículum, fue precisamente la necesidad de diseccionar la lógica intrínseca de esos dispositivos, a cuyo frente desfilan las asignaturas. Como sostenía Bernstein, no son canales asépticos en la relación sociedad-sistema educativo: sus reglas internas codifican la comunicación que ellas mismas hacen posible y, por tanto, son una condición de la producción y reproducción cultural en la escuela. Así, el malogrado sociólogo británico propuso escudriñar sus «códigos» y la «gramática recontextualizadora» que instila un genio particular a los saberes destinados a las aulas, en el trance de separarlos de sus fuentes originales e insertarlos en el seno de una institución con una historia, un ordenamiento y un funcionamiento determinados. Los principios de diferenciación y clasificación que operan en ella, sus mecanismos de control de las conductas, su organización de espacios, tiempos e interacciones, la omnipresente lógica examinadora que acaba haciendo prevalecer el valor de cambio de las enseñanzas (el precio transaccional de una calificación)

49 GonzÁlez Delgado, M.: «Notas para una evaluación... », op. cit., p. I26. 
sobre su valor de uso (su potencial para incrementar la comprensión de la realidad), etc., se convierten en catalizadores de esa curiosa «alquimia» que transmuta unos conocimientos académicos en un producto sui géneris para uso escolar ${ }^{50}$. Es imposible aprehender en profundidad el currículum haciendo abstracción de la sociedad y de las ciencias coligadas. Pero también es imposible hacerlo sin un análisis institucional.

Ahora bien, ni los arreglos institucionales ni los curriculares se reinventan desde cero cada día a partir de los encuentros, desencuentros y negociaciones de unos actores que "producirían» de este modo los patrones a seguir. Basta comparar el plan de estudios para Bachillerato de I847 con el vigente en la Educación Secundaria Obligatoria para advertirlo. Hablar del desarrollo de los sistemas educativos modernos y de sus asignaturas es hablar de procesos de larga duración, acompasados por la crisis y transformación de algunos rasgos y la conversión de otros en tradición duradera, establecida con tal firmeza que es admitida generalmente como el retrato "palmario» de lo que la escuela y el currículum son. Esto no es un apriorismo teórico. Es la constatación fáctica de una muy abundante investigación empírica. La cuestión es explicarla, y para ello hace falta una teoría de la acción. Raimundo Cuesta se ha apoyado sobre todo en la teoría disposicional de la acción de Bourdieu. Nosotros lo hemos hecho en la teoría de la estructuración de Giddens ${ }^{\text {SI }}$. Mariano González Delgado, en una noción instrumental e individualista de la acción. Desde el punto de vista de la dialéctica agencia-estructura, lo que esta noción opone al «orden» no es el conflicto, sino el azar y la contingencia absolutos, en sí contradictorios con la persistencia demostrada por tantas inercias, convenciones y rutinas escolares y curriculares. Las personas nos constituimos como actores en los propios escenarios sociales en que nos desenvolvemos día a día, y tales escenarios están atravesados por pautas institucionalizadas de comportamiento asentadas e interiorizadas. Somos reflexivos, entendidos e intencionales, pero poner todo el énfasis en las ideas e intereses que guían la acción implica olvidar que la acción y las circunstancias de la acción configuran también nuestras ideas, preformando y confinando nuestro entendimiento de lo que es factible y deseable. La práctica de los docentes no es solo el producto de sus inclinaciones y experiencias personales o de su razón estratégica, sino además una construcción social, histórica y política: construimos nuestra práctica tanto como la práctica es construida por el marco en el que acaece. Nuestros desempeños cotidianos son el medio a través del cual se produce y reproduce el currículum, pero este los antecede y los sobrepasa. Soslayar esto incapacita para penetrar en la densa textura del currículum corporeizado de facto en las

so La idea de la alquimia está tomada de Popkewitz. Puede verse una aclaración de su sentido en Pereyra, M. Á.: «The Meaning of Scholardship. An Intellectual Interview with Tom Popkewitz», en Pereyra, M. Á. y Franklin, B. M. (eds.): Systems of Reason and the Politics of Schooling, New York, Routledge, 20I4, pp. 67-IIO.

sI Cfr. Romero, J.: «Conocimiento escolar, ciencia, institución y democracia», Education Policy Analysis Archives / Archivos Analíticos de Politicas Educativas, 22(2I) (2014), pp. I-30. 
aulas y en los mecanismos formales e informales de socialización profesional. Lo cual, a su vez, reduce peligrosamente la virtualidad formativa que la historia del currículum pudiera tener para los futuros maestros. Consiéntasenos otra breve digresión al respecto.

El hecho de que seamos agentes del currículum explica lo que hay de implícito en nuestro pensamiento acerca de él. Y como señalaba Bourdieu, únicamente la ilusión de la omnipotencia de nuestro raciocinio puede hacer creer que la duda más radical sea suficiente para dejar en suspenso esas presuposiciones que influyen en nuestra visión de las cosas. «Lo inconsciente es la historia: la historia colectiva, que ha producido nuestras categorías de pensamiento, y la historia individual, por medio de la cual nos han sido inculcadas» ${ }^{52}$. Este debería ser, en nuestra opinión, el terreno de la historia del currículum. Pero, para que lo sea, tendría que ocuparse menos de la historia que pasa y más de la historia que pesa en nuestras instituciones, en nuestras actuaciones y en nuestra conciencia. Por desgracia, no es una orientación que se prodigue entre los historiadores de la educación.

Semejante afirmación no conlleva rehuir en absoluto el examen de los conflictos y del cambio. Todo lo contrario. Nosotros mismos hemos indagado sobre la vida de algunos proyectos innovadores puestos en marcha hace casi medio siglo ${ }^{53}$. Pero la aspiración era proporcionar alguna luz al debate actual sobre las reformas en curso y, al tiempo, sobre los múltiples condicionantes que labran la suerte de una innovación curricular. Cabe sostener como hipótesis plausible que este acceso histórico a problemas del presente (que nada tiene que ver con el presentismo) puede interesar a profesores en formación o en ejercicio. Pero tampoco suele ser esta la orientación predominante entre los historiadores de la educación. En cualquier caso, investigar el cambio no significa sobrevalorar lo que eventualmente haya de novedoso en leyes y propuestas. Este es un desliz frecuente, debido a varias causas. A menudo, los colegas de este gremio cuentan con un conocimiento limitado de las tradiciones didáctico-curriculares que han contendido históricamente en el interior de cada asignatura por la definición de lo deseable, dentro de un reparto muy asimétrico de los recursos materiales, simbólicos y de autoridad. Apenas han lanzado sobre la Academia, y en general sobre los fabricantes/ difusores de discurso curricular, una mirada sociológica como la empleada por Bourdieu en Homo Academicus, tan alejada de las habituales visiones que este autor tacha de «ensimismadas» ${ }^{54}$. Añádase a lo anterior su propensión a acotar

52 Bourdieu, P.: Meditaciones pascalianas, Barcelona, Anagrama, 1999, p. 23.

s3 Romero, J. y Louzao, M.: «Educación para una ciudadanía intercultural y rendición de cuentas. Una mirada desde la historia de las asignaturas escolares», Espacio, Tiempo y Educación, 4(2) (2OI7), Pp. I2I-I42.

54 Bourdieu, P.: Homo Academicus, Madrid, Siglo XXI, 2008. No carecemos de modelos específicos, foráneos y autóctonos, para este tipo de miradas. Desde la temprana contribución de Kliebard a un volumen colectivo -impulsado por Thomas S. Popkewitz- muy importante en el desarrollo de este subcampo en EE. UU. (Kliebard, H. M. y Wegner, G.: «Harold Rugg and the Reconstruction of the Social Studies Curriculum: The Treatment of the 'Great War' in his Textbook Series», en Popkewitz, T. S. [d.]: The Formation of School Subjects. The Struggle for Creating an 
lapsos temporales coincidentes con determinados capítulos de la historia política, una decisión que torna más difícil captar «las complejas interrelaciones entre los propósitos y los procesos del cambio institucional»s5. A consecuencia de todo ello, se suele confundir reforma con mudanza efectiva y reformas de primer orden con reformas de segundo orden. Esta es una distinción muy útil de Cuban ${ }^{56}$ : las primeras persiguen mejorar o hacer más eficiente lo existente, corrigiendo disfunciones, atrasos o deficiencias percibidas, pero sin poner en entredicho las categorías centrales en las que descansan los códigos del conocimiento escolar. Por ejemplo, actualizar científicamente los contenidos de una asignatura, dando por sentados -valga ahora la terminología de Bernstein- los criterios de clasificación y encuadramiento implícitos acostumbrados. Las segundas buscarían reestructurar en profundidad el fondo y la forma del currículum, en aras de otra selección y organización del saber y otra idea, no retórica, de cultura para todos. Pues bien, la inmensa mayoría de reformas curriculares emprendidas en España han sido reformas de primer orden, bastantes de las cuales ni siquiera arraigaron. El ojo inocente no ve, sin las gafas adecuadas.

\section{Reflexiones finales}

Como es notorio, hablar del currículum no es solo hablar de planes de estudio y programaciones. Además de lo prescrito, escrito, diseñado o deseado, el concepto engloba también la ardua dialéctica entre intenciones y hechos; esto es, el currículum «abrazado efectivamente» en la práctica, el representado o llevado a cabo en las interacciones entre profesores y alumnos a través de un incierto juego de interpretaciones, negociaciones, actuaciones, rituales, controles, acomodaciones, omisiones, resistencias o rechazos que lo reconstruyen en el espacio físico e institucionalmente estructurado de las aulas, modelando el tipo de experiencias «educativas»-expresas y tácitas- ofrecidas o negadas de facto a los discentes. En otras palabras, tratamos con una realidad poliédrica y escurridiza que se crea, recrea y disputa en varias instancias con ritmos dispares. Para intentar atrapar esa complejidad, en nuestras pesquisas hemos adaptado ad hoc un esquema heurístico de Stephen Ball con vistas a conjugar los distintos contextos involucrados en su configuración evolutiva: a) el "contexto de influencia», en el cual los distintos agentes con interés en el currículum movilizan sus redes, canales de resonancia y estrategias de presión para procurar hacer valer su voz en los ámbitos donde se decide la política educativa; b) el «contexto de producción de las regulaciones y

\footnotetext{
American Institution, Philadelphia, Falmer Press, 1987, pp. 268-287), hasta la aportación de John P. Ivens al monográfico que el lector tiene en sus manos, por continuar con el mismo país. Pasando, entre nosotros, por el clarificador trabajo de MAINER, J.: La forja de un campo profesional..., op. cit.

"Tyack, D. y Cuban, L.: En busca de la utopía. Un siglo de reformas de las escuelas públicas, México D.F., Fondo de Cultura Económica, 20or, p. 9.

${ }_{56}$ Cuban, L.: «Curriculum stability and change», en Jackson, P. W. (ed.): Handbook of Research on Curriculum, New York, MacMillan, 1992, pp. 216-247.
} 
demás textos curriculares», en alusión no solo a los documentos oficiales y directrices administrativas, sino también a los manuales y cualesquiera otros proyectos y materiales didácticos; c) el «contexto de las prácticas», que coparticipa en la producción del conocimiento impartido a través de los mecanismos de recontextualización mencionados más arriba; y d) el «contexto de los resultados», referido al poso duradero -más allá de los aprendizajes y memorizaciones pasajeros- que la aculturación escolar deja en las personas. Cada contexto es internamente conflictivo y, aunque todos se relacionan entre sí, sus vínculos son imprecisos, laxos e incluso hostiles, en absoluto unidireccionales ni sincrónicos ${ }^{57}$. Dentro de ese campo de fuerzas el currículum cobra forma, se reproduce o se altera.

Por descontado, cada «contexto» (y cada elemento integrante del mismo) constituye un nivel de análisis legítimo. Nada más lejos de nuestro ánimo que discutir semejante obviedad. Pero, sin unas lentes teóricas que ayuden a interpretar y situar lo analizado dentro de ese intrincado conjunto, aumenta el riesgo de que las conclusiones parciales induzcan a equívoco. Aunque nos acerquen a la naturaleza histórica y socialmente construida de este dispositivo cultural -antídoto imprescindible contra el falso sentido común que naturaliza y esencializa el conocimiento escolar-, quizá sean insuficientes para propiciar esa «ruptura con la experiencia nativa» ${ }^{8}$ que tenemos como sujetos escolarizados. Cuando ese, a nuestro juicio, es el principal servicio que puede prestar una buena historia del currículum.

57 Véase un ejemplo del distinto ritmo temporal de tales contextos en el rastreo histórico de la «pedagogía del entorno» que acometimos en ROMERO, J. y LuIs, A.: «El conocimiento socio-geográfico en la escuela: las tensiones inherentes a la transmisión institucionalizada de cultura y los dilemas de la educación para la democracia en este mundo globalizado», Scripta Nova, XII (270-I23) (2008), pp. I-I9. Disponible en http://www.ub.edu/geocrit/sn/sn-270/sn-270-I23.htm.

${ }_{58}$ Bourdieu, P.: Homo Academicus, op. cit., p. II. 